\title{
Extraction and Characterization of Natural Dye from Green Walnut Shells and Its Use in Dyeing Polyamide: Focus on Antibacterial Properties
}

\author{
Mohammad Mirjalili ${ }^{1}$ and Loghman Karimi ${ }^{2}$ \\ ${ }^{1}$ Department of Textile Engineering, Yazd Branch, Islamic Azad University, Yazd, Iran \\ ${ }^{2}$ Young Researchers and Elites Club, Science and Research Branch, Islamic Azad University, Tehran, Iran \\ Correspondence should be addressed to Mohammad Mirjalili; dr.mirjalili@iauyazd.ac.ir
}

Received 26 May 2013; Revised 8 July 2013; Accepted 8 August 2013

Academic Editor: Beatriz Oliveira

Copyright ( $) 2013$ M. Mirjalili and L. Karimi. This is an open access article distributed under the Creative Commons Attribution License, which permits unrestricted use, distribution, and reproduction in any medium, provided the original work is properly cited.

\begin{abstract}
Extraction of dyes from walnut using Soxhlet apparatus has been studied. The color components extracted and isolated from walnut shells were characterized by column chromatography, thin layer chromatography (TLC), nuclear magnetic resonance (NMR), mass spectroscopy (MS), and infrared (IR) techniques. Natural dye extract obtained from the walnut was used in dyeing polyamide fabrics with different mordants. The dyed fabrics were evaluated for antibacterial activity against pathogenic strains of Grampositive (Staphylococcus aureus) and Gram-negative (Escherichia coli) bacteria. As such, the relationship between antibacterial activity and dye concentration is investigated. Durability of antibacterial activity to laundering is also discussed. Results indicate that the polyamide dyed with walnut displayed excellent antibacterial activity in the presence of ferric sulfate, cupric sulfate, and potassium aluminum sulfate and exhibited good and durable fastness properties.
\end{abstract}

\section{Introduction}

Nowadays, the interest for antimicrobial textiles has significantly increased due to their potential to provide a higher level of hygiene in home areas and safety benefits to people $[1,2]$. Textile materials provide ideal environment for growth and multiplication of pathogenic microbes leading to unpleasant odor, dermal infection, weakening of the substrate, discoloration, allergies, and other related diseases [3]. For this reason, there is an urgent need for a potentially effective means to control and/or inhibit microbiological growth to protect both the wearer and textiles. Antimicrobial textiles can be used to produce many goods such as sportswear, working clothes, undergarments, shoes linings, carpets, upholstery, hospital linens, wound care wraps, towels, and toys for children [4]. Antibacterial finishes can have potential benefits to contain the spread of disease, avoid the danger of injury-induced infection, and prevent the deterioration of textiles and have other advantages [5].
A number of techniques have already been employed to impart antibacterial activity to textiles. These techniques include fluorocarbon repellent finish $[6,7]$, chemical binding of heterocyclic $\mathrm{N}$-halamine functional group $[8,9]$, using plasma [10], and immobilisation of antibacterial metallic nanoparticles on textiles [11-13]. Although the synthetic antibacterial agents are very effective against a range of microbes, they are causes of concerns due to health hazards, action on nontarget microorganisms, and environmental pollution [14].

Natural dyes are believed to be safe because of their nontoxic, nonallergic, and biodegradable nature [15-17]. Many of the plants used for dye extraction are classified as medicinal, and some of them have recently been shown to possess remarkable antibacterial activity $[18,19]$. According to the literature, plants such as Curcuma longa L. [20-22], Lawsonia inermis [22, 23], Rheum emodi L. [24], Catechu [14], Quercus infectoria Oliv. [25], Punica granatum peel [26], Saraca asoca [27], Albizia lebbeck [27], and so forth produce pigments 
which have widespread applications in textile dyeing industries and represent probable alternative to synthetic dyes and artificial antimicrobial agents. Walnut (Juglans regia L.), that is used as a coloring agent, has antibacterial properties [2831]. The dyeing principle in extracts from green walnut shells and walnut leaves is 5-hydroxy-1,4-naphthoquinone (juglon, CI 75500) [32]. Dyeing textile substrates with aqueous walnut extracts yields brown shades [33]. Little attention has been given to the antibacterial dyeing of textiles using walnut as a natural dye. Recently, Shahmoradi Ghaheh et al. dyed wool fabric with extracted walnut and proved antibacterial properties of wool fabric [26].

Polyamides form an interesting polymer class with many applications, such as fibers, engineering plastics, films, and coatings. Major advantages of polyamide are high modulus and strength, stiffness, stretch, wrinkle, and abrasion resistances [34]. However, polyamide can easily be attacked by bacteria in vivo $[8,9]$. In this study, nontoxic and ecofriendly dye was extracted from walnut shells using soxhlet apparatus, and antibacterial polyamide fabrics were prepared by natural dyeing in the presence of various mordants. We also focused on the antibacterial activity of dyed fabrics against two common pathogenic bacteria: Escherichia coli (E. coli) and Staphylococcus aureus (S. aureus).

\section{Experimental}

2.1. Materials and Apparatuses. The polyamide (nylon 6.6) fabric was used with warp density 50 ends/cm and weft density 28 ends $/ \mathrm{cm}$. The chemical solvents (standard materials) were used for identification purposes; chloroform, ethanol, silica gel, petroleum ether, diethyl ether, $n$-hexane, and acetone were purchased from Merck. Potassium aluminum sulfate, cupric sulfate, and ferric sulfate as mordants were purchased from Merck. E. coli, a Gram-negative bacterium, was selected due to its popularity as a test organism and its resistance to common antibacterial agents. S. aureus, a pathogenic Gram-positive bacterium, was used because it was the major cause of crossinfection in hospitals and it is the most frequently evaluated species. Cultures of following microorganisms were used in the study: S. aureus ATCC 25922, E. coli ATCC 25923.

NMR spectra were obtained by ${ }^{1} \mathrm{H}$ NMR $300 \mathrm{MHz}$, spectrophotometer $\left(\mathrm{CDCl}_{3}\right)$, infrared (IR) taken by Shimadzu 470, mass spectrometry (MS) taken by Quattro LC (Micromass, Manchester, UK), and TLC method by aluminum sheet, silica gel $60 \mathrm{~F}_{25 \mathrm{u}}$ was done. UV-vis spectroscopic analyses were performed on a Varian-Cary 100 spectrophotometer. Ahiba Polymat dyeing machinery was used for dyeing the samples.

2.2. Chromatography. At first, we employed the soxhlet apparatus which was employed to extract the colorant from walnut shellsby ethanol solvent. The colorant dissolved in ethanol was collected by means of rotary evaporator and the collected extract was mixed with silica gel (silica gel $60 \mathrm{~F}_{25 \mathrm{u}}$ ) in order to be converted into colorant powder.
The colorant powder was immersed into column chromatograph, and then it was washed by different mixed solvents from nonpolar to polar; petroleum ether, $n$-hexane/petroleum ether, petroleum ether/diethyl ether, diethyl ether, diethyl ether/chloroform, chloroform, chloroform/ethanol, ethanol, and acetone.

The total number of samples used at this stage was 27 pieces, and in order to distinguish the number of spots on silica sheet $(2 \times 4.5 \mathrm{~cm})$, each of these samples was tested by thin layer chromatography (TLC) method. Samples with similar and equal spots were mixed together and numbered. To separate and analyze the numbered colorant samples, they were set like spots on a line on a silica sheet. The spotted silica sheet was then immersed in a TLC tank and the sheet was washed by a suitable predetermined solvent. This caused the separation of different color bases from the main line and the formation of different thin bands. Then the $R_{f}$ for each band was calculated (Table 1).

In order to separate the colorant from the silica sheet, the thin bands were cut and put into the acetone or methanol solvent and then they were filtered.

To ensure that the samples (dye liquor) contain the same product, the samples were again tested by TLC again (petroleum ether/chloroform $(95: 5 \mathrm{v} / \mathrm{v})$ ).

TLC experiments showed that some of these samples still contained several spots that were again separated.

Finally, the different functional groups of these samples were identified by IR, NMR, and MS methods.

2.3. Dyeing Procedure. To study the relationship between dye concentration and antibacterial activity, $100 \%$ polyamide fabrics with $1,3,5$, and 10 on weight of fabric percent (O.W.F.) were dyed by the extracted dye with mordant and without mordant. The polyamide fabric was dyed in an Ahiba dyeing system with the walnut dye. The dye bath comprised of dye, $1 \%$ acetic acid, and 3\% mordant. The liquor ratio was kept at $40: 1$. The temperature was raised to $100^{\circ} \mathrm{C}$ by a thermal gradient of $2^{\circ} \mathrm{C} \mathrm{min}^{-1}$, and dyeing operation continued for $60 \mathrm{~min}$.

2.4. Color Measurements. Dyed polyamide fabrics were individually tested for their color strength. The color strength $(K / S)$ values of the dyed fabrics were instrumentally determined by reflectance spectrophotometer (BYK-Gardner, India, with CIELAB 1976 color space and D65-light source) with Kubelka-Munk equation as follows:

$$
\frac{K}{S}=\frac{(1-R)^{2}}{2 R},
$$

where $R$ is the reflectance of the dyed fabric at the maximum absorption wavelength, $S$ is the scattering coefficient, and $K$ is the absorption coefficient of the dyed fabrics.

2.5. Antibacterial Test. Antibacterial activity against Grampositive bacteria ( $S$. aureus) and Gram-negative bacteria (E. coli) was tested quantitatively by AATCC Test Method 100-1999. The number of viable bacteria colonies on the agar 


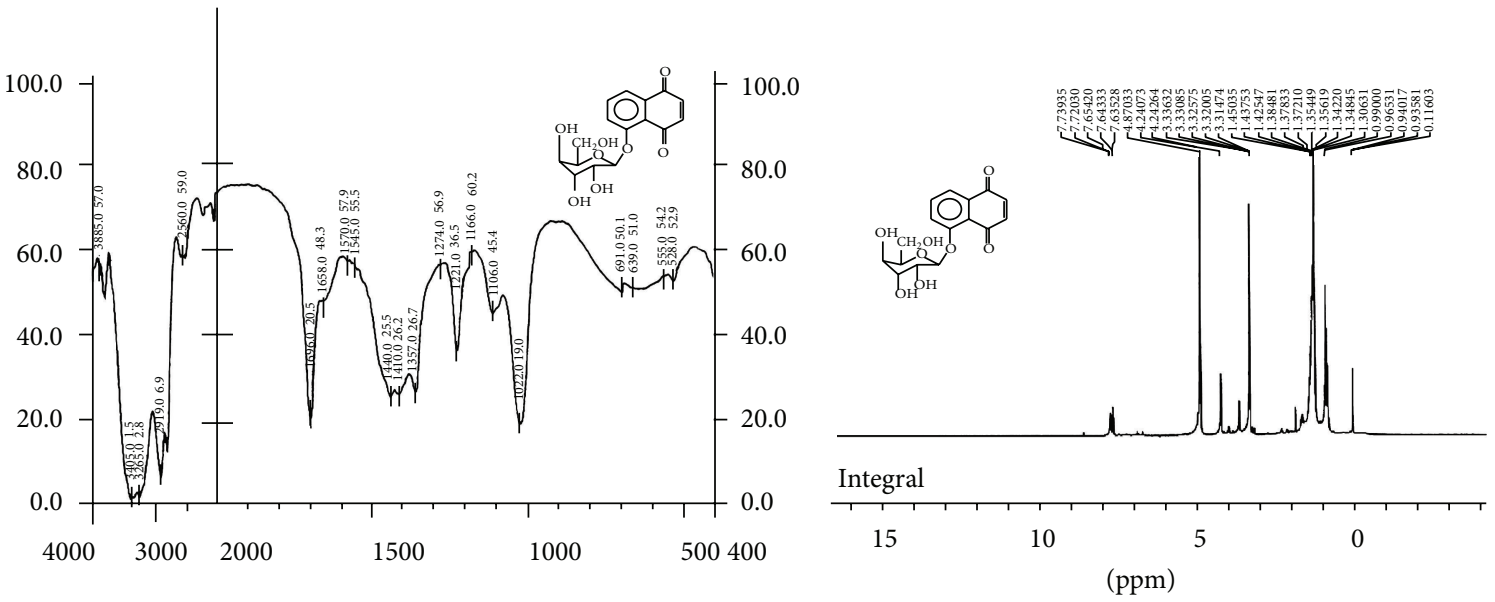

(a)

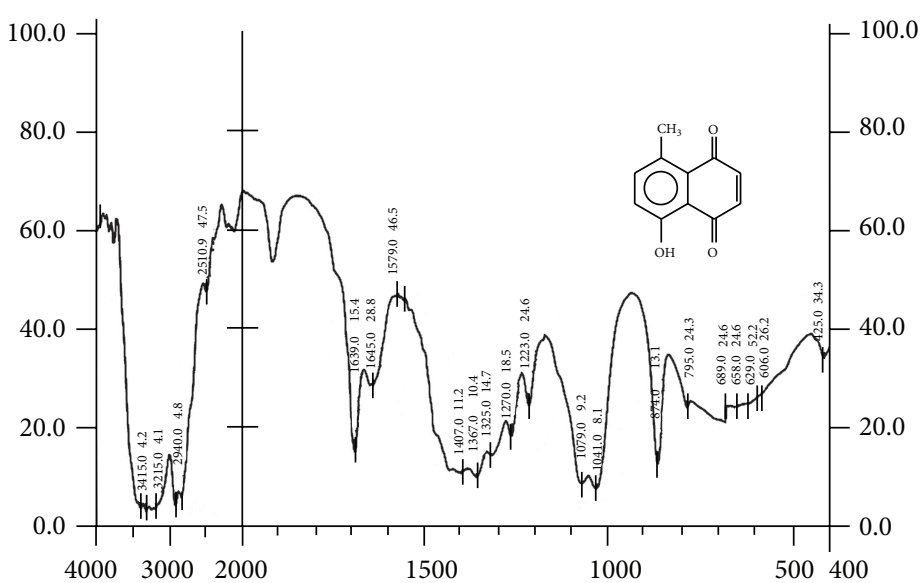

(b)

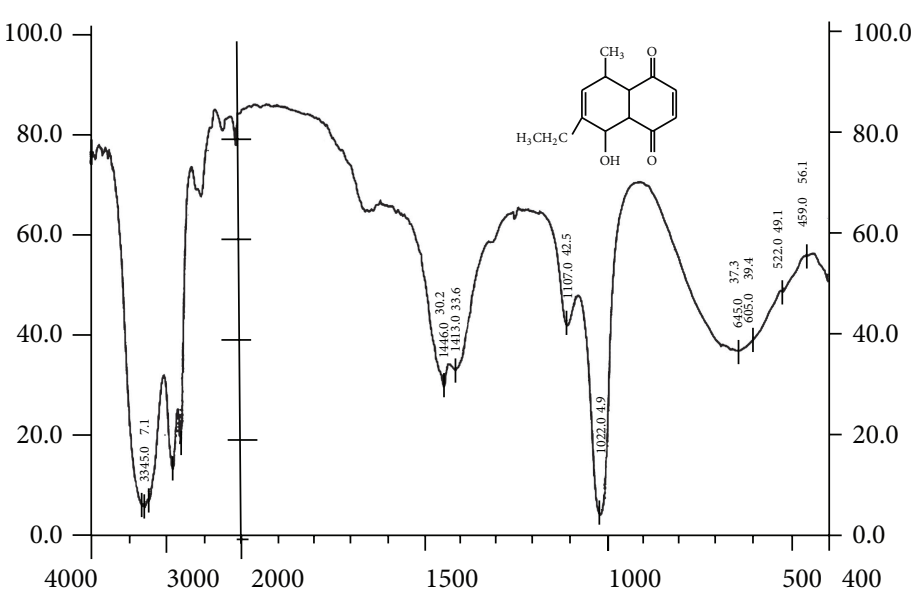

(c)

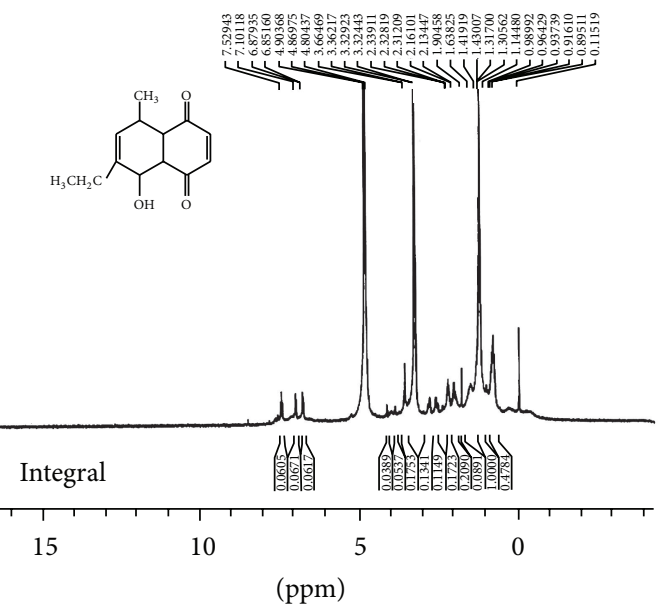

FIGURE 1: IR and NMR spectra from the extracted dye: (a) $n$-hexane/petroleum ether $(90: 10, \mathrm{v} / \mathrm{v}), R_{f}=0.32$, (b) petroleum ether/diethyl ether $(50: 50, \mathrm{v} / \mathrm{v}), R_{f}=0.68$, and (c) petroleum ether/diethyl ether $(55: 45, \mathrm{v} / \mathrm{v}), R_{f}=0.64$. 
TABLE 1: Comparison $R_{f}$ of some base colors in the walnut dye.

\begin{tabular}{lcc}
\hline Sample & Solvent & $R_{f}$ \\
\hline $1-4$ & $n$-Hexane/petroleum ether $(95: 5, \mathrm{v} / \mathrm{v})$ & $R_{f}=0.61$ \\
$5-10$ & Petroleum ether/diethyl ether $(50: 50, \mathrm{v} / \mathrm{v})$ & $R_{f}=0.89, R_{f}=0.79, R_{f}=0.74, R_{f}=0.68, R_{f}=0.22, R_{f}=0.50$ \\
$11-15$ & Petroleum ether/Diethyl ether $(55: 45, \mathrm{v} / \mathrm{v})$ & $R_{f}=0.76, R_{f}=0.64, R_{f}=0.29, R_{f}=0.18, R_{f}=0.08$ \\
$16-21$ & $n$-Hexane/petroleum ether $(90: 10, \mathrm{v} / \mathrm{v})$ & $R_{f}=0.42, R_{f}=0.32, R_{f}=0.21, R_{f}=0.11$ \\
$22-27$ & Petroleum ether & $R_{f}=0.47, R_{f}=0.12$ \\
\hline
\end{tabular}

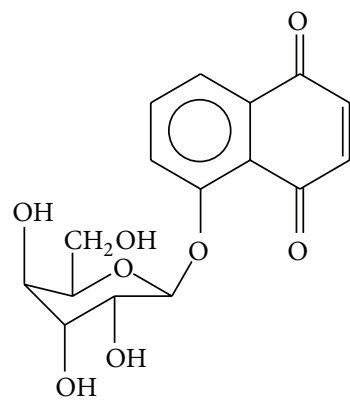

(a)<smiles>Cc1ccc(O)c2c1C(=O)C=CC2=O</smiles>

(b)<smiles>CCc1cc(C)c2c(c1O)C(=O)C=CC2=O</smiles>

(c)

Figure 2: Chemical structures of the extracted dye from the walnut shells with different solvents: (a) $n$-hexane/petroleum ether (90:10, v/v), $R_{f}=0.32$, (b) petroleum ether/diethyl ether $(50: 50, \mathrm{v} / \mathrm{v}), R_{f}=0.68$, and (c) petroleum ether/diethyl ether $(55: 45, \mathrm{v} / \mathrm{v}), R_{f}=0.64$.

plate was counted before and after dyeing and the results were reported as percentages of bacteria reduction according to

$$
R=\frac{(B-A)}{B} \times 100
$$

where $R$ denotes the percentage of reduction of microbial population, $B$ is the absorbance of the media inoculated with microbes and undyed fabric, and $A$ shows the absorbance of the media inoculated with microbes and dyed fabric.

2.6. Durability to Laundering. Durability of antibacterial finishing to washing is one of the major concerns of textile researchers and users because textiles are subjected to frequent laundering. To determine the washing fastness, the dyed samples with $10 \%$ concentration of the walnut were washed with successive washings at $60^{\circ} \mathrm{C}$ for $20 \mathrm{~min}$ using a solution containing $1 \mathrm{~g} / \mathrm{L}$ nonionic detergent (Ultravon GPN, Ciba Co, Germany). Samples were finally rinsed with distilled water thoroughly and dried at room temperature. The durability of antibacterial finishing was studied through antibacterial tests after $1,5,10$, and 20 cycles laundering. In order to increase validation of these examinations, every test was duplicated.

\section{Result and Discussion}

3.1. Identification of Coloring Compounds. Considering the results from IR and NMR spectra shown in Figure 1, and when the color bases extracted from the walnut by ethanol solvent were purified with the mentioned methods, the following items were produced (Figure 2).
3.2. Mass Spectroscopy. Mass spectroscopy was used to identify the compound of the extracted walnut dye by ethanol. As shown in Figure 3, mass spectra were presented as percent of ion frequency $(\mathrm{m} / \mathrm{z})$.

Most compound ions in the ionization place have the highest peak in value spectra which is called "the base peak," while the other peaks in spectra are observed to be the mainpeaks. With regard to the weld mass spectra, by breaking the base molecular of dye and converting it into molecular ions, the molecular compound and the molecular weight can be obtained. As observed in the presented graphs, this can introduce the molecular bound breaking mechanism (Figure 4).

3.3. Color Strength of Polyamide Fabrics. The wavelength of maximum absorption of the walnut dye extracted by ethanol solution was $360 \mathrm{~nm}$. The majority of natural dyes need a mordant in the form of a metal salt to create an affinity between the fiber and the pigment. These metals form a ternary complex on one side with the fiber and on the other side with the dye. Such a strong coordination tendency enhances the interaction between the fiber and the dye, resulting in high dye uptake. Figure 5 shows the graph of treated samples $K / S$ dyed by the extracted walnut dye $(5 \%)$. The results of dyeing samples show that using mordants considerably increased dye absorption leading to higher $K / S$ values in case of mordanted samples compared with unmordanted ones. Ferric sulfate mordant was found to have the most prominent effect on color strength.

3.4. Antibacterial Activity. Antibacterial activities of raw and the dyed samples against both $E$. coli and $S$. aureus bacteria 

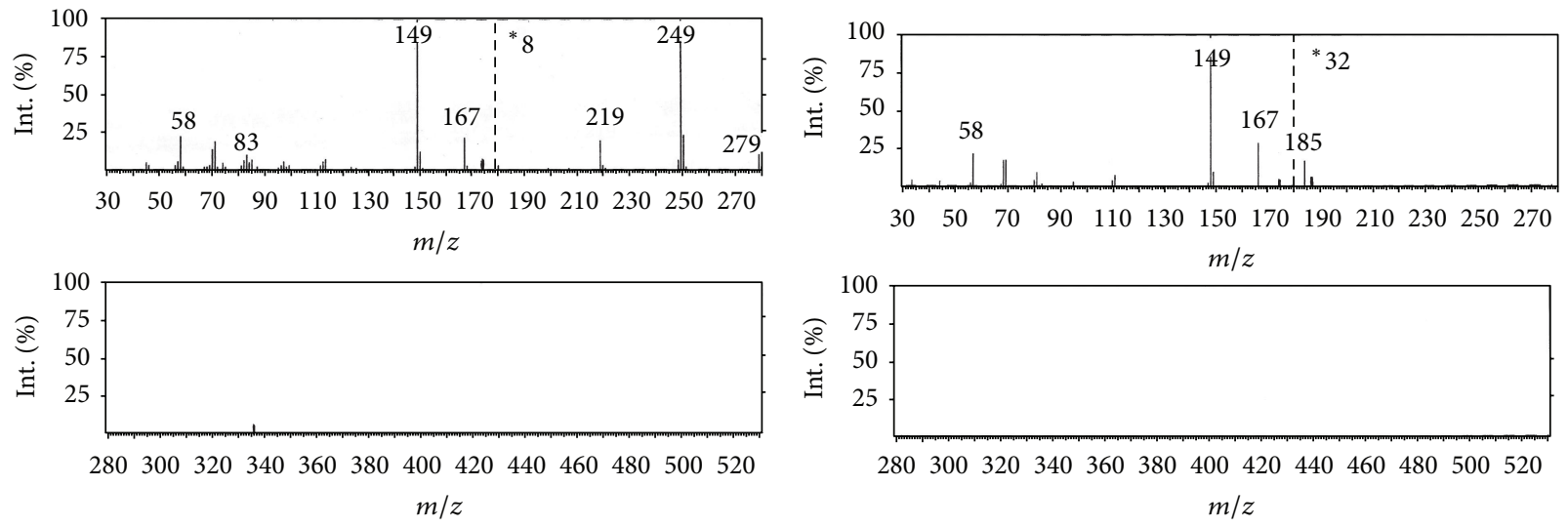

(a)

(b)

FigURE 3: MS graphs of the extracted dye: (a) $n$-hexane/petroleum ether ( $90: 10, \mathrm{v} / \mathrm{v}), R_{f}=0.32$ and (b) petroleum ether/diethyl ether ( $50: 50$, $\mathrm{v} / \mathrm{v}), R_{f}=0.68$.

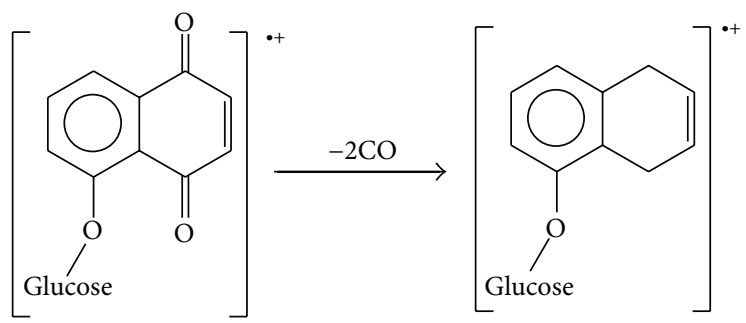

279

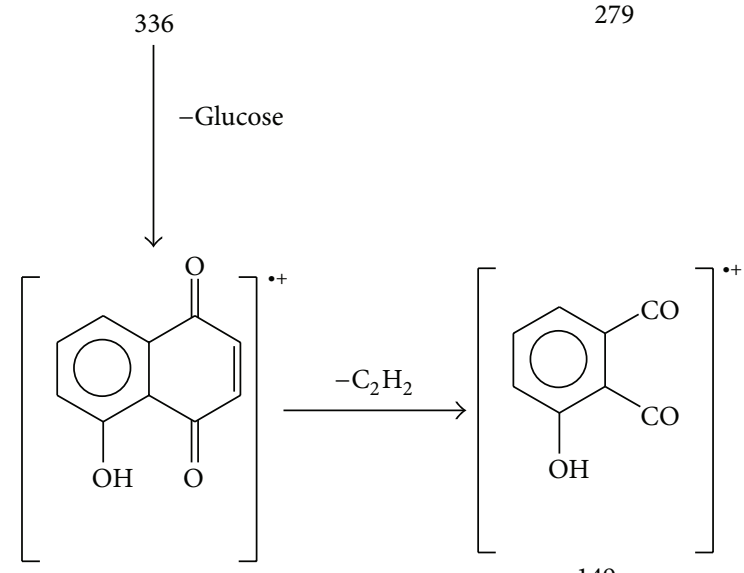

175

(a)

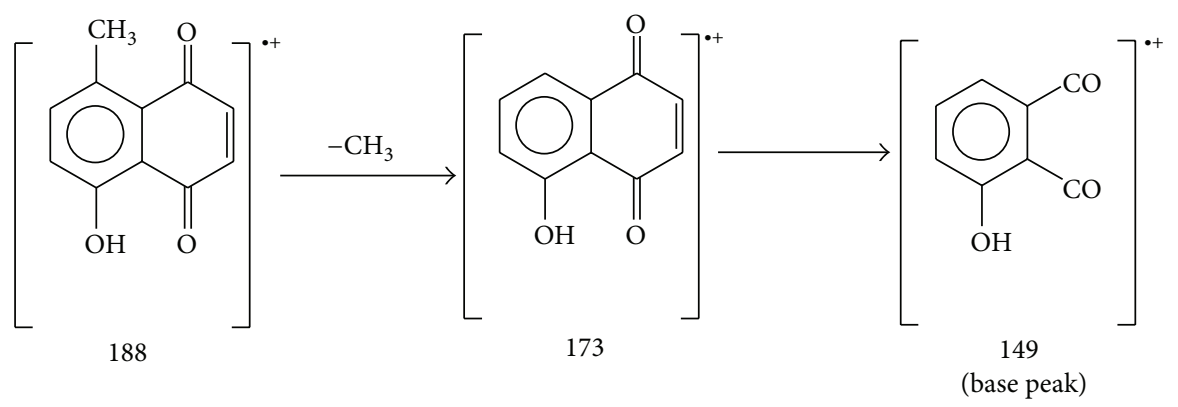

(b)

FIGURE 4: MS fragmentations of the extracted dye: (a) $n$-hexane/petroleum ether $(90: 10, \mathrm{v} / \mathrm{v}), R_{f}=0.32$ and (b) petroleum ether/diethyl ether $(50: 50, \mathrm{v} / \mathrm{v}), R_{f}=0.68$. 




Figure 5: $K / S$ graph of the dyed polyamide fabric samples with 5\% walnut (O.W.F.): (1) un-mordanted, (2) potassium aluminum sulfate, (3) cupric sulfate, and (4) ferric sulfate.

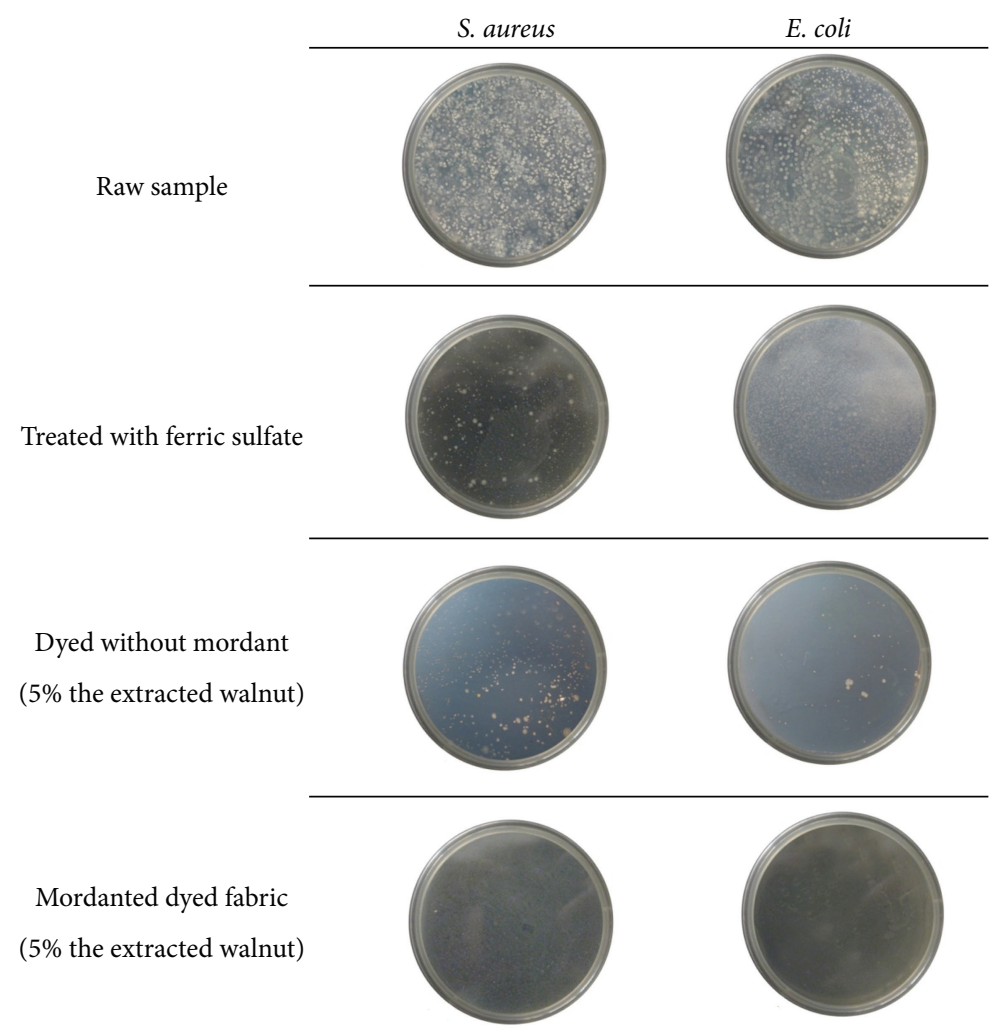

FIGURE 6: The antibacterial activity of the blank and treated samples.

were examined. The $S$. aureus bacterium is a pathogenic microorganism causing many illnesses such as purulence, toxic shock, fibrin coagulation, endocarditic, and abscess. Furthermore, it is resistant to common antibacterial agents [35]. Moreover, E. coli bacterium that causes wound infections and urinary tract is a popular test organism [36].

Figure 6 reveals the higher antibacterial properties on the mordanted dyed fabrics in comparison with other samples. It was observed that the dyed fabric with the walnut dye along with mordant in comparison with dyed fabric with the walnut dye alone and also the treated fabric with mordant had a higher antibacterial activity. Figure 6 shows the growth of bacteria on the blank sample whereas the growth of the bacteria was inhibited by the mordanted dyed fabric. In other words, the raw polyamide sample exhibits no antibacterial activity against both $E$. coli and $S$. aureus microorganisms.

Table 2 shows the antibacterial activities ( $R \%)$ of polyamide fabrics dyed with the walnut in different conditions against E. coli and S. aureus.

The antibacterial activity of dyed fabrics was ranked as ferric sulfate $>$ cupric sulfate $>$ potassium aluminum sulfate $>$ without mordant against $S$. aureus and cupric sulfate $>$ ferric sulfate $>$ potassium aluminum sulfate $>$ without mordant against $E$. coli. 
TABLE 2: Reduction percentage of E. coli and S. aureus in different conditions (each experiment was repeated five times).

\begin{tabular}{lcccccccc}
\hline & \multicolumn{9}{c}{ Reduction percent $(R \% \pm \mathrm{SD})$} \\
$\begin{array}{l}\text { The extracted walnut } \\
\text { concentration (O.W.F.\%) }\end{array}$ & $\begin{array}{c}\text { Cupric } \\
\text { sulfate }\end{array}$ & $\begin{array}{c}\text { Ferric } \\
\text { sulfate }\end{array}$ & Potash alum & $\begin{array}{c}\text { Without } \\
\text { mordant }\end{array}$ & $\begin{array}{c}\text { Cupric } \\
\text { sulfate }\end{array}$ & $\begin{array}{c}\text { Ferric } \\
\text { sulfate }\end{array}$ & $\begin{array}{c}\text { Potash } \\
\text { alum }\end{array}$ & $\begin{array}{c}\text { Without } \\
\text { mordant }\end{array}$ \\
\hline $1 \%$ & $75.27 \pm 1$ & $80.05 \pm 1$ & $74.11 \pm 1$ & $74.57 \pm 4$ & $96.38 \pm 0.2$ & $91.19 \pm 1$ & $83.07 \pm 2.5$ & $40.63 \pm 7$ \\
$3 \%$ & $86.66 \pm 1$ & $93.07 \pm 1$ & $84.19 \pm 2$ & $81.91 \pm 3$ & $97.47 \pm 0.1$ & $96.07 \pm 1$ & $95.35 \pm 1$ & $75.91 \pm 3$ \\
$5 \%$ & $89.29 \pm 2$ & $98 \pm 0.5$ & $96.61 \pm 1$ & $97.17 \pm 1$ & $99.94 \pm 0.1$ & $98 \pm 1$ & $96.52 \pm 1$ & $90.75 \pm 0.5$ \\
$10 \%$ & $96.85 \pm 1$ & $100 \pm 0$ & $97.53 \pm 0.5$ & $97.47 \pm 1$ & $100 \pm 0$ & $99 \pm 0.2$ & $97.91 \pm 0.2$ & $92 \pm 1$ \\
\hline
\end{tabular}

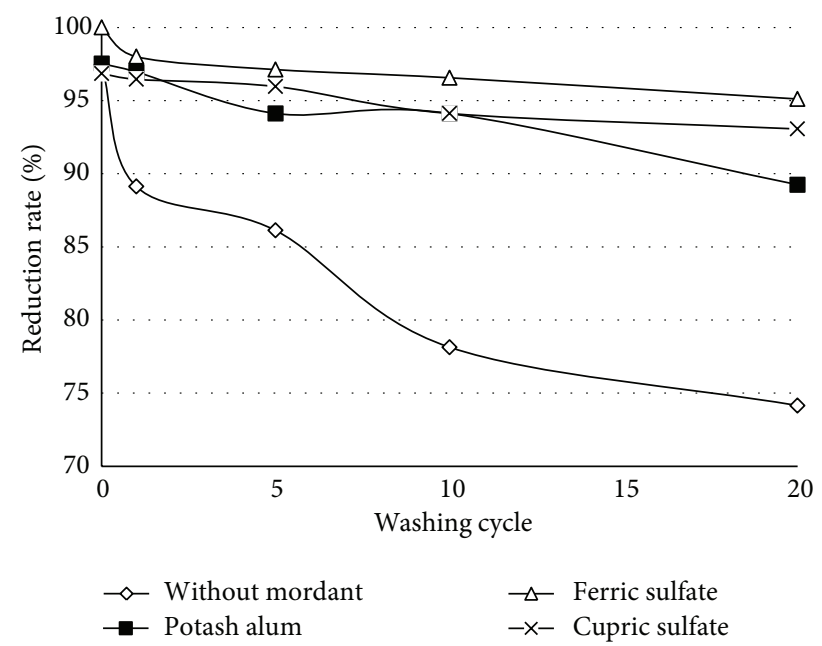

FIGURE 7: Antibacterial activity of dyed polyamide samples with $10 \%$ walnut dye against $S$. aureus after laundering.

Based on the obtained results, specimens showed better efficiency against $E$. coli in comparison with $S$. aureus. This can be explained by the difference between thicknesses of the cell walls. S. aureus has a thicker cell wall [37]. They also showed that using mordant had better antibacterial activity. It is well known that the metallic salts used as mordants exhibit toxic effects against the pathogens [38].

According to the literature, phenolic and naphthoquinone compounds possess distinct antibacterial activities $[28,30,39-43]$. The results acquired indicate that the increase in dye concentration had a tangible effect on antibacterial activity of dyed fabrics. Therefore, observed enhancement on the antibacterial activity of treated fabrics is thought to be explained on the basis of the increase in phenolic and naphthoquinone compounds.

Natural dyes are nontoxic, biodegradable and do not cause pollution and waste water problems while synthetic dyes have been known to cause health hazards due to their carcinogenic effects. Hence, it is suggested that the walnut dye can be used for dyeing polyamide as an alternative to the very expensive, synthetic, and toxic dyes and antibacterial agents.

3.5. Washing Fastness Properties. Textiles are subjected to frequent washing, rubbing, and sweating during their use and the requirement of durability is a very important parameter.

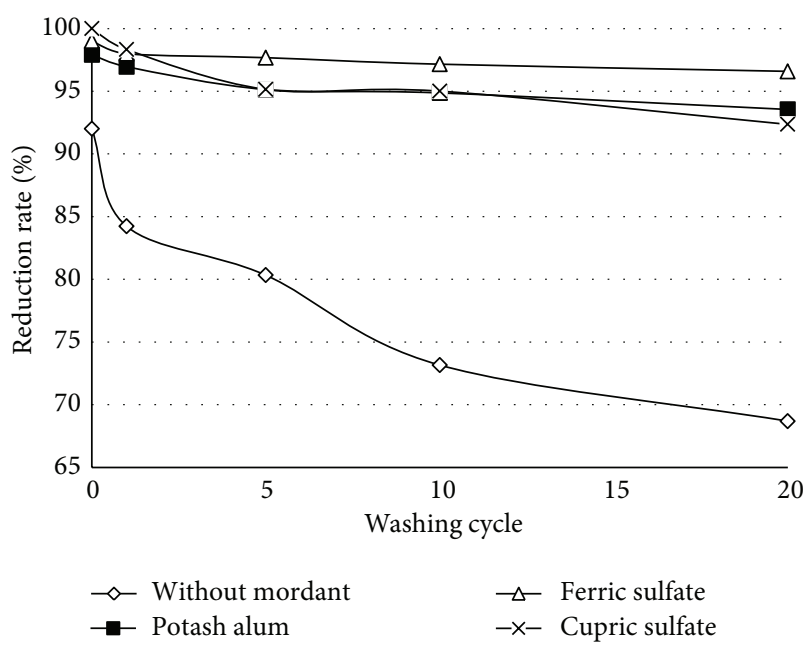

FIGURE 8: Antibacterial activity of dyed polyamide samples with $10 \%$ walnut dye against $E$. coli after laundering.

Figures 7 and 8 depict the durability of antibacterial activity after repeated home launderings. As shown, the antibacterial activity is reduced with increased number of washing cycles. The inhibition rate of treated sample without mordant was more reduced than the treated sample with mordant after laundering. The mordants form a ternary complex on one side with the fiber and on the other side with the dye. Such a strong coordination tendency enhances the interaction between the fiber and the walnut dye.

\section{Conclusions}

This study mainly focused on the dye extraction from walnut shells, identification, and the quality of its use as a dye with polyamide. A common dyeing process imparts color and antimicrobial property to dyed polyamide. Since the dyeing process and antibacterial finishing have been conducted in one step and do not require an additional step, this method becomes very cost effective. Natural dyed polyamide fabrics exhibit excellent antibacterial activity against two well-known pathogenic bacteria S. aureus and E. coli. Mordants have shown to have a positive effect on antimicrobial activity of dyed samples. Moreover, wash durability of antimicrobial finishing was considerably improved by mordanting. 


\section{References}

[1] R. Dastjerdi and M. Montazer, "A review on the application of inorganic nano-structured materials in the modification of textiles: focus on anti-microbial properties," Colloids and Surfaces B, vol. 79, no. 1, pp. 5-18, 2010.

[2] L. Windler, M. Height, and B. Nowack, "Comparative evaluation of antimicrobials for textile applications," Environment International, vol. 53, pp. 62-73, 2013.

[3] R. Purwar and M. Joshi, "Recent developments in antimicrobial finishing of textiles-a review," AATCC Review, vol. 4, no. 3, pp. 22-26, 2004.

[4] Y. Gao and R. Cranston, "Recent advances in antimicrobial treatments of textiles," Textile Research Journal, vol. 78, no. 1, pp. 60-72, 2008.

[5] D. Gupta and S. Bhaumik, "Antimicrobial treatments for textiles," Indian Journal of Fibre and Textile Research, vol. 32, no. 2, pp. 254-263, 2007.

[6] L. F. Hao, Q. F. An, W. Xu, and Q. J. Wang, "Synthesis of fluorocontaining superhydrophobic cotton fabric with washing resistant property using nano- $\mathrm{SiO}_{2}$ sol-gel method," Advanced Materials Research, vol. 121-122, pp. 23-26, 2010.

[7] M. Yu, G. Gu, W. D. Meng, and F. L. Qing, "Superhydrophobic cotton fabric coating based on a complex layer of silica nanoparticles and perfluorooctylated quaternary ammonium silane coupling agent," Applied Surface Science, vol. 253, no. 7, pp. 3669-3673, 2007.

[8] J. Keskin, K. Winkelman, S. D. Worley, R. M. Broughton, and J. F. Williams, "Antimicrobial treatment of nylon," Journal of Applied Polymer Science, vol. 81, no. 4, pp. 943-947, 2001.

[9] L. Qian and G. Sun, "Durable and regenerable antimicrobial textiles: synthesis and applications of 3-methylol-2,2,5,5tetramethylimidazolidin-4-one (MTMIO)," Journal of Applied Polymer Science, vol. 89, no. 9, pp. 2418-2425, 2003.

[10] M. Mirjalili and L. Karimi, "The impact of nitrogen low temperature plasma treatment upon the physical-chemical properties of polyester fabric," Journal of the Textile Institute, vol. 104, no. 1, pp. 98-107, 2013.

[11] A. Hebeish, M. E. El-Naggar, M. M. G. Fouda, M. A. Ramadan, S. S. Al-Deyab, and M. H. El-Rafie, "Highly effective antibacterial textiles containing green synthesized silver nanoparticles," Carbohydrate Polymers, vol. 86, no. 2, pp. 936-940, 2011.

[12] J. Kiwi and C. Pulgarin, "Innovative self-cleaning and bactericide textiles," Catalysis Today, vol. 151, no. 1-2, pp. 2-7, 2010.

[13] T. Nakashima, Y. Sakagami, H. Ito, and M. Matsuo, "Antibacterial activity of cellulose fabrics modified with metallic salts," Textile Research Journal, vol. 71, no. 8, pp. 688-694, 2001.

[14] M. I. Khan, A. Ahmad, S. A. Khan et al., "Assessment of antimicrobial activity of Catechu and its dyed substrate," Journal of Cleaner Production, vol. 19, no. 12, pp. 1385-1394, 2011.

[15] F. A. Nagia and R. S. R. EL-Mohamedy, "Dyeing of wool with natural anthraquinone dyes from Fusarium oxysporum," Dyes and Pigments, vol. 75, no. 3, pp. 550-555, 2007.

[16] P. S. Vankar and R. Shanker, "Eco-friendly pretreatment of silk fabric for dyeing with Delonix regia extract," Coloration Technology, vol. 125, no. 3, pp. 155-160, 2009.

[17] M. Mirjalili, K. Nazarpoor, and L. Karimi, "Eco-friendly dyeing of wool using natural dye from weld as co-partner with synthetic dye," Journal of Cleaner Production, vol. 19, no. 9-10, pp. 1045-1051, 2011.
[18] R. Singh, A. Jain, S. Panwar, D. Gupta, and S. K. Khare, "Antimicrobial activity of some natural dyes," Dyes and Pigments, vol. 66, no. 2, pp. 99-102, 2005.

[19] A. K. Prusty, T. Das, A. Nayak, and N. B. Das, "Colourimetric analysis and antimicrobial study of natural dyes and dyed silk," Journal of Cleaner Production, vol. 18, no. 16-17, pp. 1750-1756, 2010.

[20] S. M. Ghoreishian, L. Maleknia, H. Mirzapour, and M. Norouzi, "Antibacterial properties and color fastness of silk fabric dyed with turmeric extract," Fibers and Polymers, vol. 14, no. 2, pp. 201-207, 2013.

[21] M. Mirjalili and L. Karimi, "Antibacterial dyeing of polyamide using turmeric as a natural dye," AUTEX Research Journal, vol. 13, no. 2, pp. 51-56, 2013.

[22] N. A. Ibrahim, A. R. El-Gamal, M. Gouda, and F. Mahrous, "A new approach for natural dyeing and functional finishing of cotton cellulose," Carbohydrate Polymers, vol. 82, no. 4, pp. 1205-1211, 2010.

[23] M. Yusuf, A. Ahmad, M. Shahid et al., "Assessment of colorimetric, antibacterial and antifungal properties of woollen yarn dyed with the extract of the leaves of henna (Lawsonia inermis)," Journal of Cleaner Production, vol. 27, pp. 42-50, 2012.

[24] S. A. Khan, A. Ahmad, M. I. Khan et al., "Antimicrobial activity of wool yarn dyed with Rheum emodi L. (Indian Rhubarb)," Dyes and Pigments, vol. 95, no. 1, pp. 206-214, 2012.

[25] M. Shahid, A. Ahmad, M. Yusuf et al., "Dyeing, fastness and antimicrobial properties of woolen yarns dyed with gallnut (Quercus infectoria Oliv.) extract," Dyes and Pigments, vol. 95, no. 1, pp. 53-61, 2012.

[26] F. Shahmoradi Ghaheh, A. Shams Nateri, S. M. Mortazavi, D. Abedi, and J. Mokhtari, "The effect of mordant salts on antibacterial activity of wool fabric dyed with pomegranate and walnut shell extracts," Coloration Technology, vol. 128, pp. 473478, 2012.

[27] S. Baliarsingh, A. K. Panda, J. Jena, T. Das, and N. B. Das, "Exploring sustainable technique on natural dye extraction from native plants for textile: identification of colourants, colourimetric analysis of dyed yarns and their antimicrobial evaluation," Journal of Cleaner Production, vol. 37, pp. 257-264, 2012.

[28] I. Oliveira, A. Sousa, I. C. F. R. Ferreira, A. Bento, L. Estevinho, and J. A. Pereira, "Total phenols, antioxidant potential and antimicrobial activity of walnut (Juglans regia L.) green husks," Food and Chemical Toxicology, vol. 46, no. 7, pp. 2326-2331, 2008.

[29] J. A. Pereira, A. P. G. Pereira, I. C. F. R. Ferreira et al., "Table olives from Portugal: phenolic compounds, antioxidant potential, and antimicrobial activity," Journal of Agricultural and Food Chemistry, vol. 54, no. 22, pp. 8425-8431, 2006.

[30] J. A. Pereira, I. Oliveira, A. Sousa et al., "Walnut (Juglans regia L.) leaves: phenolic compounds, antibacterial activity and antioxidant potential of different cultivars," Food and Chemical Toxicology, vol. 45, no. 11, pp. 2287-2295, 2007.

[31] A. Fernández-Agulló, E. Pereira, M. S. Freire et al., "Influence of solvent on the antioxidant and antimicrobial properties of walnut (Juglans regia L.) green husk extracts," Industrial Crops and Products, vol. 42, pp. 126-132, 2013.

[32] T. Bechtold and R. Mussak, Handbook of Natural Colorants, John Wiley \& Sons, New York, NY, USA, 2009.

[33] M. Mirjalili, K. Nazarpoor, and L. Karimi, "Extraction and identification of dye from walnut green husks for silk dyeing," Asian Journal of Chemistry, vol. 23, no. 3, pp. 1055-1059, 2011. 
[34] M. Lewin, Handbook of Fiber Chemistry, CRC Press, Boca Raton, Fla, USA, 2007.

[35] R. Dastjerdi, M. Montazer, and S. Shahsavan, "A new method to stabilize nanoparticles on textile surfaces," Colloids and Surfaces A, vol. 345, no. 1-3, pp. 202-210, 2009.

[36] M. Montazer, A. Behzadnia, E. Pakdel, M. K. Rahimi, and M. B. Moghadam, "Photo induced silver on nano titanium dioxide as an enhanced antimicrobial agent for wool," Journal of Photochemistry and Photobiology B, vol. 103, no. 3, pp. 207214, 2011.

[37] V. A. Nadtochenko, A. G. Rincon, S. E. Stanca, and J. Kiwi, "Dynamics of E. coli membrane cell peroxidation during $\mathrm{TiO}_{2}$ photocatalysis studied by ATR-FTIR spectroscopy and AFM microscopy," Journal of Photochemistry and Photobiology A, vol. 169, no. 2, pp. 131-137, 2005.

[38] G. McDonnell and A. D. Russell, "Antiseptics and disinfectants: activity, action, and resistance," Clinical Microbiology Reviews, vol. 12, no. 1, pp. 147-179, 1999.

[39] J. A. Pereira, I. Oliveira, A. Sousa, I. C. F. R. Ferreira, A. Bento, and L. Estevinho, "Bioactive properties and chemical composition of six walnut (Juglans regia L.) cultivars," Food and Chemical Toxicology, vol. 46, no. 6, pp. 2103-2111, 2008.

[40] J. A. Pereira, A. P. G. Pereira, I. C. F. R. Ferreira et al., "Table olives from Portugal: phenolic compounds, antioxidant potential, and antimicrobial activity," Journal of Agricultural and Food Chemistry, vol. 54, no. 22, pp. 8425-8431, 2006.

[41] H. Gerson, "Fungitoxicity of 1,4-naphthoquinones to Candida albicans and Trichophyton mentagrophytes," Canadian Journal of Microbiology, vol. 21, no. 9, pp. 1317-1321, 1975.

[42] A. R. Schuerch and W. Wehrli, " $\beta$-lapachone, an inhibitor of oncornavirus reverse transcriptase and eukaryotic DNA polymerase- $\alpha$," European Journal of Biochemistry, vol. 84, no. 1, pp. 197-205, 1978.

[43] H. Wagner, B. Kreher, H. Lotter, M. O. Hamburger, and G. A. Cordell, "Structure determination of new isomeric naphtho[2,3-b]furan-4,9-diones from tabebuia avellanedae by the selective-INEPT technique," Helvetica Chimica Acta, vol. 72, no. 4, pp. 659-667, 1989. 

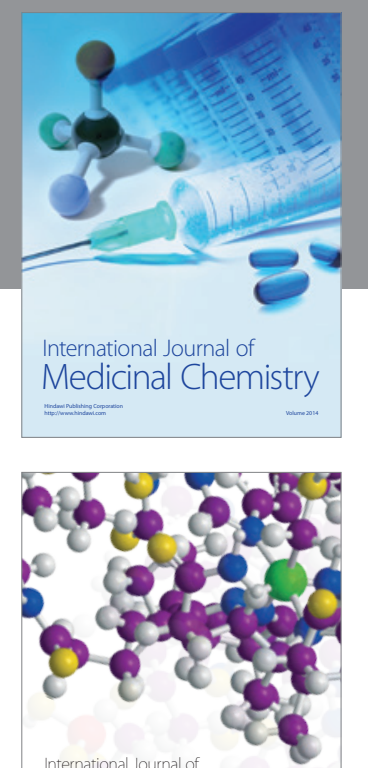

\section{Carbohydrate} Chemistry

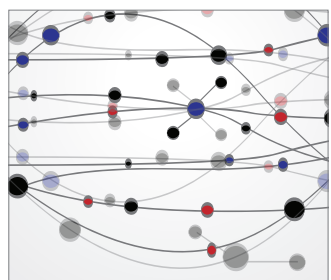

The Scientific World Journal
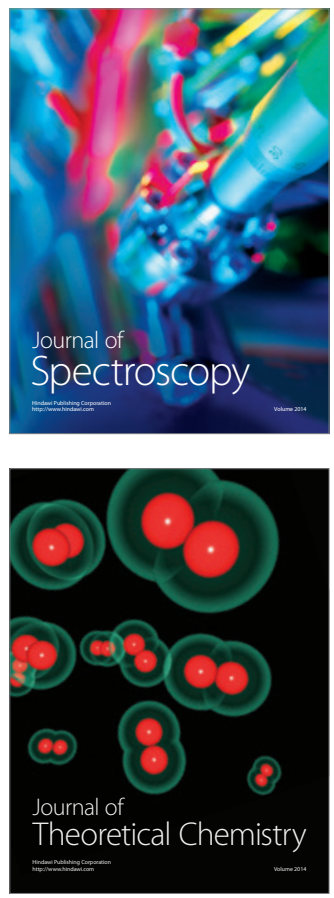
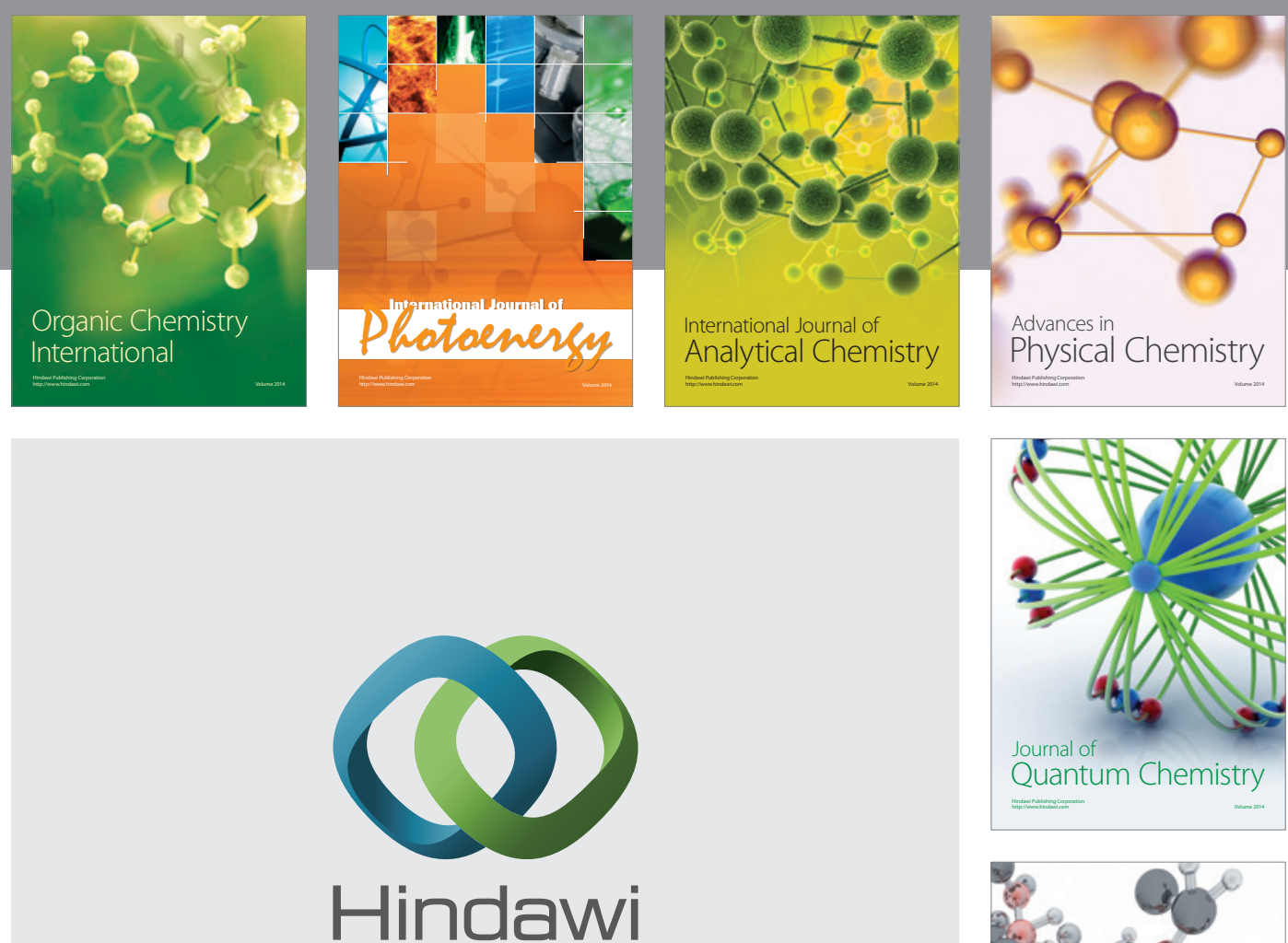

Submit your manuscripts at

http://www.hindawi.com

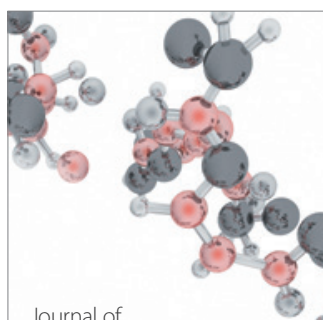

Analytical Methods

in Chemistry

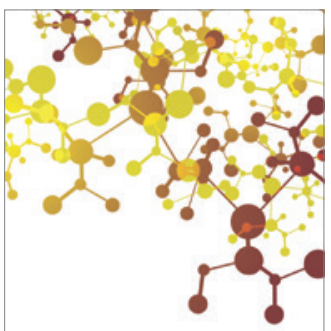

Journal of

Applied Chemistry

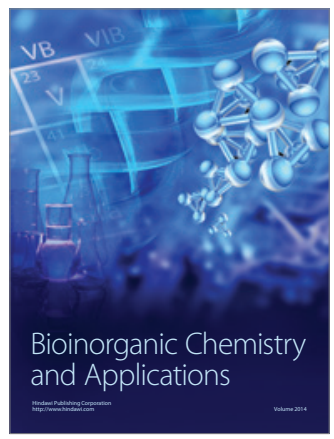

Inorganic Chemistry
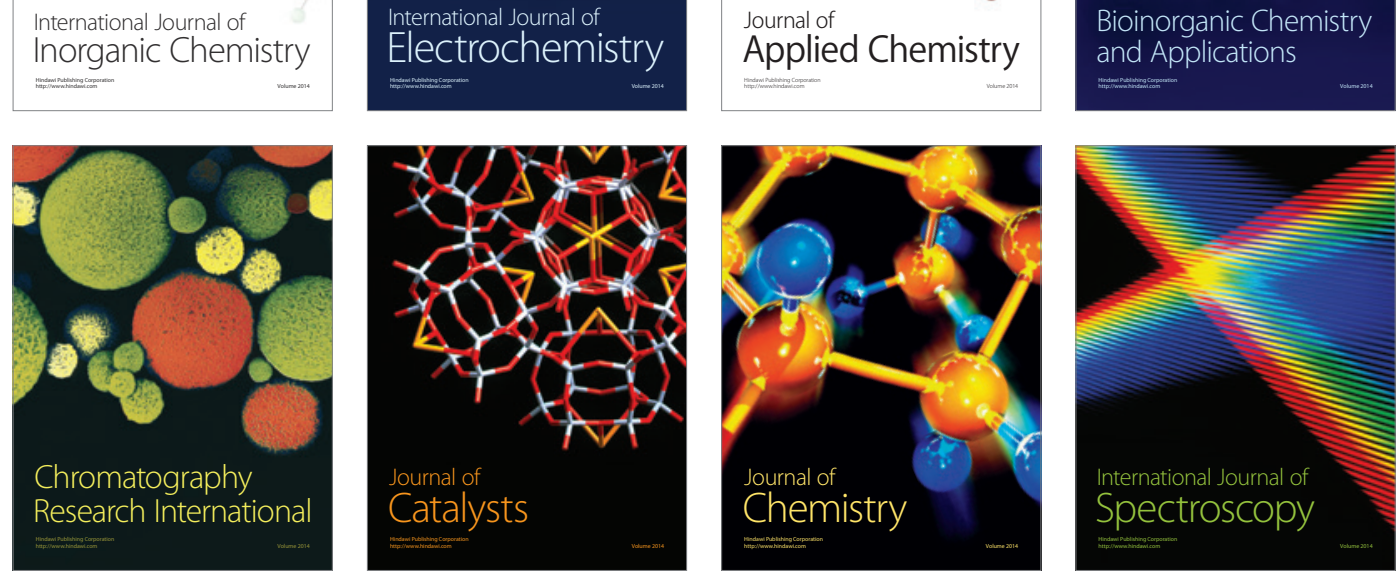